\title{
Erratum
}

\section{The emergence of long-lasting transients of activity in simple neural networks}

\author{
A. van Ooyen ${ }^{1}$, J. van Pelt ${ }^{1}$, M. A. Corner ${ }^{1}$, and F. H. Lopes da Silva ${ }^{2}$ \\ 1 Netherlands Institute for Brain Research, Meibergdreef 33, 1105 AZ Amsterdam, The Netherlands \\ 2 Department of Experimental Zoology, University of Amsterdam, The Netherlands
}

Biol. Cybern. 67, 269-277 (1992)

Due to an unfortunate error the name of the first author was misspelled. The name should read A. van Ooyen, as above. 